\title{
The natural history of naive T cells from birth to maturity
}

\author{
Benedict Seddon ${ }^{1}$ And Andrew J. Yates $^{2}$ \\ ${ }^{1}$ Institute of Immunity and Transplantation, Division of Infection and Immunity, UCL, Royal Free Hospital, \\ Rowland Hill Street, London NW3 2PF, United Kingdom \\ ${ }^{2}$ Department of Pathology and Cell Biology, Columbia University Medical Center, 701 West 168th Street, New York, \\ NY 10032, USA
}

Address correspondence to either author; benedict.seddon@ucl.ac.uk, andrew.yates@columbia.edu

Running title: The natural history of naive $\mathrm{T}$ cells

Keywords: T cells, thymic development, mathematical modelling

\begin{abstract}
Summary
Generating and maintaining a diverse repertoire of naive $\mathrm{T}$ cells is essential for protection against pathogens, and developing a mechanistic and quantitative description of the processes involved lies at the heart of our understanding of vertebrate immunity. Here we review the biology of naive $\mathrm{T}$ cells from birth to maturity and outline how the integration of mathematical models and experiments has helped us to develop a fuller picture of their life-histories.
\end{abstract}

\section{1 | Introduction}

$\mathrm{T}$ cells are a key component of the adaptive immune system and have the capacity to specifically recognise pathogens and mount a sterilising immune response to the infection. The persistence of specific $\mathrm{T}$ cells after an immune response is the basis of immunological memory, and for many pathogens a single infectious encounter results in life-long immunity to further exposures. The diverse repertoire of antigen receptors expressed by $\mathrm{T}$ cells represents a potent weapon for the immune system but also introduces unique challenges. Generation and maintenance of the naive (antigen-inexperienced) $\mathrm{T}$ cell compartment is a complex, multi-staged process, that must balance repertoire diversity with self-tolerance. Con- sequently, there has been great interest in understanding the developmental processes responsible for generating and maintaining this repertoire. Much of this work has been qualitative, identifying the extrinsic signals and genetic programmes that direct different stages of $\mathrm{T}$ cell development. However almost all stages of a T cell's life history are fundamentally dynamic, arising from a series of balances between production, death or differentiation. Measuring the relative contributions of these processes and how each of them responds to physiological perturbations is important for understanding how vertebrates maintain large, diverse and tolerant $\mathrm{T}$ cell populations. Here we review examples of how quantitative approaches have contributed to a deeper understanding of naive $\mathrm{T}$ cell development and maintenance, from early stages in the thymus through to the periphery.

\section{Quantitative aspects of thymic development}

Since the population biology of $\mathrm{T}$ lymphocytes as a whole involves very large numbers of cells, the majority of modelling approaches have employed ordinary differential equations (ODEs) to track the expected sizes of the population(s) of interest as they 
undergo division, death or differentiation. The interpretation of the parameters in these models is then usually straightforward, although the expression for the expected time taken for cells to pass successfully through a sequence of maturation steps are perhaps unintuitive (Box 1). In what follows we highlight the methodology only in the few instances in which probabilistic, stochastic or agent-based models have been used.

\section{1 | Thymic $\mathbf{T}$ cell precursors - lin- eage choices and expanding the repertoire}

T cells develop from haematopoetic progenitors that reside in the bone marrow. Uncommitted lymphoid progenitors then migrate to the thymus as early thymic progenitors (ETP), where they can commit to a $\mathrm{T}$ lineage cell fate. Prior to $\mathrm{T}$ lineage commitment, ETP have the potential to develop into B cells, NK cells and dendritic cell lineages, and thymic NK and DC populations are physiologically recognised products of these early progenitors. The stages of $\mathrm{T}$ cell development in thymus are extremely well characterised $^{1,2}$ and illustrated in Figure 1. Briefly, expression of $\mathrm{CD} 4$ and $\mathrm{CD} 8$ co-receptors provides a low resolution overview of the process. Progenitors enter the thymus as double negative (DN) for both coreceptors, but upregulate both following successful rearrangement of $\mathrm{Tcr}$ genes and expression of a mature TCR to become CD4 CD8 double positive (DP). These DP cells then undergo a selection process that identifies cells with functional TCRs and then correlates onward lineage development into the CD4 or CD8 lineage with MHC restriction, resulting in down-regulation of CD4 in class I restricted cells to give CD8 lineage T cells, and the loss of CD8 expression by Class II restricted cells to give rise to CD4 lineage T cells.

The DN compartment includes early progenitor $\mathrm{T}$ cells that commit to the $\mathrm{T}$ cell lineage and start the process of Trcb gene arrangements that give rise to mature TCR structures. Expression of functional TCR $\beta$ chains stimulates cells to undergo extensive cell division and expansion, resulting in the generation of the large numbers of DPs required to audition for selection. These different stages of DN development can be conveniently identified on the basis of CD25 and CD44 expression. ETP enter the thymus and fall within the $\mathrm{CD} 44^{+} \mathrm{CD} 25^{-}$ (DN1) phenotype, further identified by expression of $\mathrm{cKit}^{3}$. Commitment to the $\mathrm{T}$ cell lineage occurs in $\mathrm{CD} 44^{+} \mathrm{CD} 25^{+}$(DN2) cells, which can further be divided into cells that retain NK and dendritic cell potential ${ }^{4,5}$ (DN2a) and those fully committed to $\mathrm{T}$ lineage (DN2b). Trcb gene rearrangement occurs in cells with a CD44- $\mathrm{CD} 25^{+}$(DN3) phenotype, which can also be further divided into those that have successfully rearranged their Trcb gene (DN3b) and those attempting to do so (DN3a). At this stage, it also possible for Tcrd and Trcg genes to be rearranged and divert development to a $\gamma \delta \mathrm{T}$ cell lineage. Successful expression of a mature $\operatorname{TCR} \beta$ in complex with the preT $\alpha$ receptor then drives a burst of cell division, and development through a CD $44^{-} \mathrm{CD} 25^{-}$ (DN4) phenotype. Division continues as DN4 cells upregulate CD8 and CD4 coreceptors to become DP cells, a stage we turn to in the next section.

While the DN compartment is one of the smallest in the thymus, it is the one in which cells spend the longest time, and various quantifications and models of progression through the DN stages are in general agreement regarding the timescales involved. Our own studies, tracking progeny of congenically marked haematopoietic stem cells in the steady state, suggest that it takes up to two weeks for the first donor cells to appear in DN2 and DN3 stages, and a further 2-3 weeks for complete turnover of the DN compartments ${ }^{6}$, similar to observations of using experimental transfer of thymic progenitors ${ }^{3}$. Data from the latter study were used to model the DN1-2 transition ${ }^{7}$, estimating transit times of around 10 days in DN1 and indicating that differentiation to DN2 occurs after multiple rounds of division, supported by the finding that in vitro differentiation of putative early 


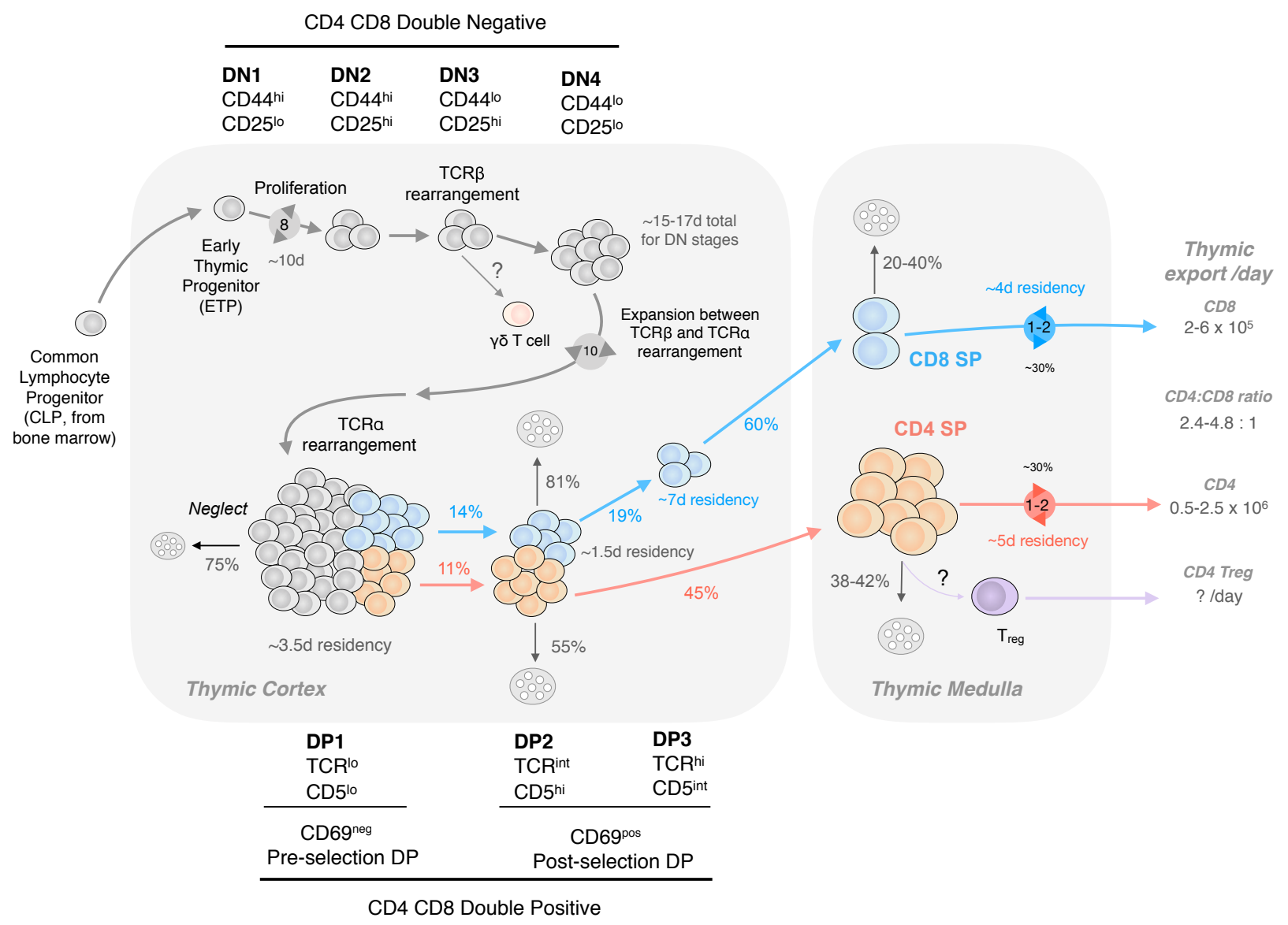

Figure 1: Mapping the development of $\alpha \beta \mathrm{T}$ cells in the thymus. Common lymphoid progenitor cells migrate from the bone marrow to the thymus where they begin a multi-stage process of development. Red and blue denote the $\mathrm{CD} 4+$ and $\mathrm{CD} 8+$ lineages of $\mathrm{TCR} \alpha \beta \mathrm{T}$ cells respectively. Discs with arrows denote the approximate number of cell divisions undergone at each stage. DN - CD4 CD8 double negative, DP CD4 CD8 double positive. 
stage Flt3+ DN1 was inefficient and required more cell divisions than later stage Flt $3^{-}$DN1 cells. Other quantitative studies have examined the DN compartment as a whole, modelling its reconstitution following depletion. Thomas-Vaslin et al. ${ }^{8}$ fitted a multicompartment ODE model of thymocyte development to data from drug induced ablation of cycling cells, which considered the four major CD4/CD8 developmental compartments (DN, DP, SP4, SP8). Souzae-Silva et $\mathrm{al}^{9}$ developed an agent-based model describing movement and behaviour of thymocytes in a 2D lattice following irradiation. These two very different approaches derived similar estimated average total DN residency times of $16-18 \mathrm{~d}$, in agreement with empirical observations ${ }^{3}$. Thomas-Vaslin et $a l .{ }^{8}$ estimated an average recruitment of 20,000 ETP per day, and that DN cells undergo an average of four cell divisions. While these parameters were sufficient to explain the size of the DN compartment size and its output, the granularity of the description may confound influx and proliferation. Studies enumerating ETP in the adult thymus reveal around 1,000 cells ${ }^{10}$ and others suggest that entry of precursors into the thymus may be episodic rather than a steady flow ${ }^{11}$. A further level of complexity comes from studies suggesting that early thymic progenitors also have self-renewing capacity ${ }^{12}$, revealed following thymus transplantation into IL7R deficient hosts that lack common lymphoid progenitors, and it is possible this capacity may serve to ensure steady thymic repopulation and output in the face of inconsistent progenitor input.
Box 1: Transit and residence times in development

When estimating the time taken for cells to progress through development, care must be taken in the interpretation of the parameters of traditional ordinary differential equation (ODE) models. Take a population $N$ that is fed at a constant rate $\theta$ from a precursor population, is at risk of death, and also matures to a downstream developmental stage. If maturation and cell death are both modelled as independent, firstorder processes, then if $\mu$ is the per capita maturation rate and $\delta$ is the rate at which they die, then we can model the dynamics of the expected number of cells in this population using

$$
\frac{\mathrm{d} N}{\mathrm{~d} t}=\theta-\mu N-\delta N
$$

Here $\mu d t$ and $\delta d t$ are the probabilities that a cell will mature or die, respectively, within a short time interval $d t$. The residence time of a cell within this developmental stage - the time it spends there whether it matures or dies - is therefore exponentially distributed with mean $1 /(\mu+\delta)$. However, the transit time - the time spent in the compartment by cells that successfully mature - follows the same distribution, also with mean $1 /(\mu+\delta)$, and not $1 / \mu$. Intuitively, if cells are at constant risk of dying, those that mature tend to do so earlier, on average, than those maturing at no risk of death. This apparent acceleration of maturation will be most apparent at developmental bottlenecks when death rates are substantial.

The DN3 stage represents a key checkpoint in development at which thymocytes that fail to undergo productive $T c r$ gene rearrangements die, and those that succeed commit to either an $\alpha \beta$ or $\gamma \delta$ lineage fate. While there are clues regarding the role of expression or signalling of the two prototypical TCRs in directing this lineage decision ${ }^{13}$, the relative probability is unknown and is obscured by the distinct proliferative fates of cells following lineage commitment. In contrast to DN4 thymocytes, $\gamma \delta \mathrm{T}$ cells do not undergo a burst of division and several distinct lineages of $\gamma \delta$ T cells emerge during ontogeny, defined by cytokine producing potential. IL-17 secreting dendritic epidermal $\gamma \delta$ T cells, that reside in the epidermis of the skin, are known to develop as a 
distinct wave only in the fetal period ${ }^{14}$. In contrast, undifferentiated and interferon-producing $\gamma \delta \mathrm{T}$ cells appear to develop in the thymus throughout life ${ }^{14}$. However, it is unclear what role this population has in the production and maintenance of peripheral $\gamma \delta$ $\mathrm{T}$ cells. In general we have little quantitative understanding of $\gamma \delta \mathrm{T}$ cell repertoire development and homeostasis, and this area is open for modelling approaches.

Following successful Tcrb rearrangements, DN3 thymocytes undergo a proliferative burst accompanied by differentiation though the DN4 stage to generate the large pool of DP thymocytes that audition for selection and onward development. Modelling recovery of thymic development following drug induced depletion of cycling cells, Thomas-Vaslin et al. ${ }^{8}$ estimated that thymocytes divide 8 times as they expand and transition from $\mathrm{DN}$ to mature $\mathrm{DP}$, and that this flux replenishes up to a third of the mature DP pool every day. This estimate is in close agreement with BrdU labelling studies that found a similar fraction of DP thymocytes labelled with BrdU overnight ${ }^{15}$ and our own studies of thymocyte development discussed below ${ }^{16}$. While it is not fully understood how this burst of cell division is controlled, there is evidence that an asymmetric cell division (ACD) following successful TCR $\beta$-selection of DN3 cells may be involved ${ }^{17}$. Scribble is a factor required for ACD, and Scribble ${ }^{-/-}$mice have a subtly enlarged DN4 compartment. Ref. 17 used mathematical models to establish that DN3 cells likely undergo at least one symmetric cell division before an ACD event. Surprisingly, DP numbers are not altered in Scribble-deficient thymocytes, suggesting that expansion of DN4 into DP may involve a degree of quorum sensing rather than an autonomous program of divisions.

\subsection{Selecting the $\operatorname{TCR} \boldsymbol{\alpha} \boldsymbol{\beta}$ reper- ${ }_{220}$ toire

At the early DP stage, re-expression of the Rag ${ }_{222}$ recombinase complex allows rearrangement of Tcra ${ }_{223}$ genes so that DPs may attempt to express a ma- ${ }_{224}$ ture $\alpha \beta$ TCR heterodimer. From this point, onward 225 development of thymocytes is restricted to those ex- 226 pressing functionally relevant TCRs. Such cells are ${ }_{227}$ identified in different selection processes, governed 228 by signals originating from newly expressed TCRs. ${ }_{229}$ A fundamental property of useful TCRs is that they 230 have a low level of intrinsic recognition of self-MHC molecules that is thought to facilitate recognition of foreign antigens in the periphery ${ }^{18}$. Onward development of such cells is termed positive selection. Because of the random nature of somatic Tcr gene arrangements, many newly generated TCRs lack any intrinsic capacity to recognise self-MHC and fail to continue development, ultimately dying 'by neglect'. Others will recognise self-peptide MHC with high affinity and have the potential to be overtly autoreactive, and die through so-called negative selection. Precisely how the TCR repertoire subdivides into useful, useless or dangerous TCRs has been of great interest for many years. The low abundance of mature SPs, at around $5 \%$ of all thymocytes, established the view that a similar fraction of DPs express useful TCRs and undergo positive selection, and that a smaller fraction are autoreactive and are negatively selected, leaving the vast majority expressing useless receptors $^{2}$. More recently, this question has been probed by different modelling approaches, discussed below, that suggest a far larger fraction of newly generated TCR are functional than previously thought.

Our own studies ${ }^{16}$ took advantage of $\mathrm{Zap}^{7} \mathrm{O}^{-/-}$ mice, who lack expression of the tyrosine kinase Zap70 that is essential for TCR signalling. Without the capacity to transmit TCR signals, thymic development is arrested at the DP stage in these mice, but it is released following artificial restoration of Zap70 expression. This system revealed three dis- 
tinct phases of DP thymocyte development, identified by expression of TCR and CD $5^{19}$. TCR ${ }^{\text {lo }} \mathrm{CD} 5^{\text {lo }}$ DP1 thymocytes represent non-selecting cells. DP2 thymocytes are $\mathrm{TCR}^{\text {med }} \mathrm{CD} 5^{\text {hi }}$ and include $\mathrm{CD} 4$ and CD8 lineage thymocytes at the earliest stage of selection (0-48hr after onset). DP3 thymocytes are $\mathrm{TCR}^{\text {hi }} \mathrm{CD} 5^{\text {med }}$ DP cells that develop 48-72h following onset of selection, and are exclusively CD8 lineage cells. Using mathematical models to analyse the dynamics with which DP and SP compartments are restored provided new insights into the bottlenecks created by positive and negative selection. Sinclair et al. ${ }^{16}$ estimated that $\sim 25 \%$ of DP1 thymocytes are positively selected but that extensive loss at DP2 and DP3 results in only $\sim 6 \%$ of DP1 thymocytes making the transition to SP. This high failure rate suggested that the extent of negative selection during the DP phase is far higher than had previously been thought. Analysis of $\mathrm{Bim}^{-/-}$mice supports this conclusion ${ }^{20}$. Bim is a pro-apoptotic protein required for induction of cell death during negative selection, and its absence leads to the accumulation of a large population of post selection DP thymocytes (defined as CD69 ${ }^{+}$DPs that include both DP2 and DP3 subsets) that apparently receive strong TCR signals, as measured by Nur77 EGFP reporter expression. Subsequent modelling of development in wild-type and $\mathrm{Bim}^{-/-}$mice in the steady state arrived at similar conclusions to those derived from our analysis of inducible development in Zap $70^{-/-}$mice - that $35 \%$ of DPs are positively selected but that as many as $92 \%$ of these fail by negative selection at the late DP stage $^{21}$.

Both Sawicka et al. ${ }^{21}$ and Sinclair et al. ${ }^{16}$ concluded that the fraction of SPs that die is lower than the proportion lost at the late DP stages $(8 \%$ or $20 \%$ of CD4 SP respectively, and $32 \%$ or $42 \%$ of CD8 SP respectively). Therefore it appears that negative selection may occur in two waves. A first large wave during the DP stage, presumably in the thymic cortex and/or during migration to the medulla, purges the repertoire of grossly autoreactive cells, of which there are many. A second wave occurs amongst SP thymocytes and results in deletion of far fewer cells, 305 but likely represents a fine tuning of the repertoire to eliminate rarer thymocytes specific for autoantigens expressed on medullary epithelial cells. This latter process is critical for self tolerance ${ }^{22,23}$. Overall, negative selection is therefore a costly process. Because the TCR is cross-reactive, intuitively the stringency of negative selection is shaped by the needs to maintain coverage of the space of foreign peptide-MHC ligands and to avoid reactivity to self. Strikingly, theoretical studies of this trade-off have yielded estimates of the optimal rate of negative selection that are remarkably close to the more empirical estimates described above (see ref. 24 for a review).

\subsection{The emergence of the CD4:CD8 ratio in the thymus}

The ratio in which CD4 and CD8 $\mathrm{T}$ cells emerge from the thymus derives in part from the lineage decision during the DP stage (see refs. 25,26 for reviews), which is influenced by the propensities of newly formed TCR to interact with MHC class I and II, and the subsequent population dynamics and stringencies of selection within each lineage. Models have helped to map how the CD4:CD8 asymmetry emerges. Sinclair et al. ${ }^{16}$ used data from thymic development in MHC class I and class II-deficient mice to infer that roughly equal numbers of positivelyselected DP1 thymocytes are class I and class-II restricted but that only $\sim 12 \%$ of class I-restricted cells in DP2 progress to SP8 while $45 \%$ of class IIrestricted cell progress to SP4. These figures were validated by comparing the survival of class I- and class II-restricted DP thymocytes following adoptive transfer into normal thymi, and by demonstrating that class I-restricted cells were more susceptible to death through over-expression of pro-apototic factors. This skewing is consistent with estimates that $6 \%$ and $1 \%$ of DPs select into the single-positive CD 4 and CD8 lineages ${ }^{8}$. In contrast, Sawicka et al. ${ }^{21}$ inferred from steady-state thymi that the CD4:8 asymmetry emerges during continued negative selection 
in the medulla, with greater loss of CD8 than CD4 SP (32\% vs $8 \%$ ) and a greater proportion of CD4 SP cells undergoing division than CD8 SP (46\% vs 27\%). While analysis of Zap70-induced development by Sinclair et al. ${ }^{16}$ also suggested greater death amongst CD8 SP, it is less clear whether differential proliferation is a significant force favouring $\mathrm{CD} 4 \mathrm{~T}$ cells. Thomas-Vaslin et al. ${ }^{8}$ estimated that comparable fractions of $\mathrm{CD} 4$ and $\mathrm{CD} 8 \mathrm{SP}$ cells undergo one or two divisions, a conclusion supported empirically ${ }^{16}$.

While there is clear evidence that a far larger fraction of Class I- than Class II-restricted thymocytes die during selection, whether this is exclusively the result of more stringent negative selection is less clear. Triggering CD8 lineage development is associated with weaker or more transient TCR signals than CD4 development ${ }^{19,27,28}$, and so it seems counterintuitive that CD8 lineage cells would be more susceptible to negative selection. On one hand, the death rate estimates of Sawicka et al. ${ }^{21}$ were in $\mathrm{Bim}^{-/-}$mice, and therefore perhaps constitute an explicit measurement of the effect of negative selection. On the other hand, thymocytes require continued TCR signalling for survival ${ }^{29}$, so it is also possible that death of class I-restricted DP thymocytes arises in part because weak self-recognition was sufficient to initiate, but not complete, the process of positive selection. In this regard, measuring levels of negative selection in class I- or class II-deficient Bim-deficient hosts would help distinguish these possibilities.

\section{$2.4 \mid$ Post-selection maturation and regulatory $\mathbf{T}$ cell development}

Modelling has estimated that SP4 and SP8 cells reside for 5-6 days and 4-6 days respectively ${ }^{8,16}$, consistent with prior empirical estimates ${ }^{19,30}$. This residence includes the later stages of negative selection, as described above, 1-2 divisions ${ }^{16,21,31}$, and further differentation before cells are mature enough for ex- port. SPs acquire the capacity to proliferate in response to TCR triggering and induce expression of surface receptors that permit lymphocytes to start recirculation, such as $\mathrm{S} 1 \mathrm{P} 1$ receptor and L-selectin (reviewed in ref. 32).

Foxp3-expressing $\mathrm{CD} 4^{+}$regulatory $\mathrm{T}$ cells $\left(\mathrm{T}_{\text {reg }}\right)$ are also crucial for maintaining self tolerance and are induced at the CD4 SP stage in a process that takes 3-4 days ${ }^{33,34}$. The mechanistic basis of the lineage decision is still unclear but it requires TCR signalling, and $\mathrm{T}_{\text {reg }}$ are thought to to be cells with relatively high self-reactivity, close to the threshold of negative selection ${ }^{35}$. Relatively few modelling studies have explored $\mathrm{T}_{\text {reg }}$ development and we do not review the literature here, but a study of ours was motivated by a striking experimental finding that cohorts of $\mathrm{T}$ cells expressing the same transgenic TCR differentiate into both conventional and regulatory cells in the same environment ${ }^{36}$. At increasing levels of availability of the TCR's agonist peptide-MHC, $\mathrm{T}_{\text {reg }}$ differentiation was progressively more favoured until numbers of both lineages decreased at high peptide densities, presumably due to heightening levels of negative selection. These observations imply there is a strong stochastic element to the TCR-mediated component of the conventional/regulatory $\mathrm{T}$ cell fate decision in the thymus. Bains et al. ${ }^{37}$ applied a probabilistic model to data from this study to probe the mechanisms by which developing $\mathrm{T}$ cells integrate information from TCR interactions to make fate decisions. Using a simple graphical argument, together with the information that TCR sensitivity changes progressively during development (see ref. 37 and references therein) they inferred that commitment can be triggered by extremely low numbers of TCR-peptide-MHC interactions, which lead to $\mathrm{T}_{\text {reg }}$ commitment if encountered while TCR sensitivity is low but deletion (negative selection) if encountered when TCR sensitivity is higher. The model shows that one does not need to invoke a need for qualitatively different signals for conventional and $\mathrm{T}_{\text {reg }}$ development, and also explains apparently paradoxical observations regarding the effect of partial and full 
TCR agonists on the efficiency of $\mathrm{T}_{\text {reg }}$ production ${ }^{38}$. Such specificity in the fate decision likely assists in the generation of tolerance to self antigens without excessive deletion of the repertoire.

\section{3 |Recent thymic emigrants}

Although maturation of SP thymocytes is critical for their export, it appears that CD4 and CD8 T cells continue to develop even after leaving the thymus as recent thymic emigrants (RTE) and are distinct from mature naive cells ${ }^{39}$. Much of our understanding of RTE biology comes from Rag2-EGFP transgenic mice, in which green fluorescent protein (GFP) expression driven from a Rag2 promoter persists in newly developed $\mathrm{T}$ cells for as long as 3 weeks ${ }^{40}$. The GFP system has revealed subtle increases in the expression of IL-7R, Qa2 and CD28 over this timeframe, although these differences are insufficient to distinguish RTE from the rest of the naive compartment. Thymocytes whose egress is prevented with the S1P agonist FTY720 continue maturation normally (Sinclair and Seddon, unpublished observations). Thus the ligands responsible for this maturation, which include type I interferons, TNF and CD70 and exert their effect through NF $\kappa$ B signalling ${ }^{41}$, must be present in both thymic and peripheral lymphoid tissues. RTE maturation therefore likely represents a continuation of processes that begin late in development in the thymus.

Functionally, RTE undergo weaker proliferative responses and secrete lower levels of effector cytokines following TCR stimulation ${ }^{40}$. The reduced expression of IL-7R by RTE in mice may impact their ability to join the mature pool, since $\mathrm{T}$ cells that fail to upregulate IL-7R exhibit reduced survival and reduced ability to undergo homeostatic cell division ${ }^{42}$. Therefore, RTE may be at competitive disadvantage compared with mature naive $\mathrm{T}$ cells. It remains an outstanding problem to establish the lifespan of RTE relative to mature naive cells and their rate of maturation. Measuring these quantities is impor- tant because the TCR diversity of the naive reportoire can only be increased by the release of new $\mathrm{T}$ cells from the thymus, and so we want to understand how rapidly and efficiently these cells join the mature naive pool.

In mice, our knowledge of RTE dynamics comes from following the fates of newly-exported cells identified using either (i) the Rag2-EGFP system, (ii) a congenic marker expressed on adoptively transferred or engrafted thymocytes, or (iii) division-linked DNA labelling. The latter is most useful in mice, in which thymocytes proliferate substantially but peripheral naive cells divide rarely, and so over short periods the naive $\mathrm{T}$ cells that have accrued label can be inferred to be enriched for RTE ${ }^{43}$.

Two important studies ${ }^{44,45}$ examined RTE and mature naive $\mathrm{T}$ cell homeostasis by transplanting additional thymi into healthy mice and quantifying the kinetics of the host and donor-derived naive CD3+ (that is, combined CD4 and CD8 naive T cell) populations. The accumulation of donor cells in the peripheral pool was close to the estimated total number of cells exported from these thymi in the previous three weeks ${ }^{45}$, and the donor derived $\mathrm{T}$ cells were lost rapidly three to four weeks after transplantation ${ }^{44}$, when donor $\mathrm{T}$ cell production ceased due to repopulation of the grafted thymi with hostderived thymocytes. The authors inferred that RTE lived for approximately three weeks and during this time were transiently exempt from homeostatic regulation, but the kinetic of their accumulation and loss could also be explained with RTE having a relatively narrow distribution of times to die. Broadly, the behaviour they observed is consistent with a simple model of the flow from thymus to RTE to mature naive $\mathrm{T}$ cells, with maturation and loss occurring in both cell populations at random. An RTE lifetime of three weeks is slightly shorter than most estimates of the population-average lifetimes of naive CD4 and CD8 $\mathrm{T}$ cells in mice ${ }^{6,46,47}$. However, later studies that tracked RTE and mature naive cells transferred into the same mouse have come to opposite conclu- 
sions regarding their relative abilities to survive ${ }^{48,49}$. These latter studies were performed in mice of different ages, and as discussed below the survival or proliferative ability of naive $\mathrm{T}$ cells likely changes with host and/or cell age. This effect may be strong enough to significantly and progressively alter the ratio of RTE lifetime to the population-average lifetime of mature naive cells as the mouse ages. A recent study ${ }^{50}$ modelled data from thymectomy, thymus transplantation, and from several deuterium labelling studies, all in mice aged around 12 weeks. Fitting models simultaneously to all three datasets, they also concluded that CD4 RTE have an expected lifespan of about 3 weeks, less than that of mature naive cells. They also estimated that the expected time for a CD4 RTE to mature is about 8.5 weeks, meaning that less than a third of them become fully functional naive cells. In contrast, van Hoeven et $a l .{ }^{50}$ did not detect a difference in lifespan between CD8 RTE and mature naive CD8 T cells.

Thomas-Vaslin et al. ${ }^{8}$ modelled both intrathymic development, as discussed above, and also maturation and homeostasis of naive $\mathrm{T}$ cells, by following cell numbers following transient depletion of dividing cells in both euthymic and thymectomised mice. They inferred that the naive compartment comprises dividing RTE undergoing a conveyor-belt sequence of two divisions, with a mean residence time of a few days, and resting, long-lived cells in roughly equal proportions. They estimate that naive $\mathrm{T}$ cell production through proliferation, which is almost exclusively within RTE in their model, is three times higher than the rate of production from the thymus, which is at odds with other estimates in which thymic export dominates over peripheral production $^{6,43,47}$. It seems likely that this discrepancy may be due to increased homeostatic proliferation following the depletion treatment, and so these dynamics are probably not reflective of RTE behaviour at steady state.

We have a relatively limited understanding of RTE dynamics in humans, in large part because their con- tribution to total peripheral production is small ${ }^{47}$ but also because, as in mice, we lack definitive phenotypic markers. A subset of naive T cells expressing CD31 is rich in $\mathrm{T}$ cell receptor excision circles (TRECs), non-replicating fragments of DNA that are by-products of the generation of the $\mathrm{T}$ cell receptor $^{51}$ and diluted within a population by cell division. The TREC content of CD31+ naive cells declines only slowly with age as thymic output falls, suggesting that CD31+ cells are rich in RTE, and the marker tends to be lost following homeostatic division ${ }^{52}$. However this process is not complete ${ }^{53}$, meaning that subsets of CD31+ positive cells and their offspring may have been resident in the periphery for some time. In line with this, Bains et $a l .{ }^{54}$ used a small dataset from healthy and thymectomised humans with a survival analysis model in which RTE maturation is linked to post-thymic cell age, to infer that there may be considerable heterogeneity in the rates of maturation of RTE, defined by the loss of expression of another putative RTE marker, protein tyrosine kinase 7 (PTK7). Taking a different approach to inferring RTE dynamics, Vrisekoop et al. ${ }^{43}$ used heavy water labelling in human volunteers to study replenishment and turnover of naive $\mathrm{T}$ cells and found that, strikingly, labelled naive $\mathrm{T}$ cells were lost extremely slowly over the 16 weeks following withdrawal of label. Their initial interpretation was that recently-produced (labelled) cells are more long-lived than the average and so RTE and naive cells produced by homeostatic proliferation are preferentially incorporated into the naive pool. The authors later showed that the most parsimonious explanation of these observations is that naive $\mathrm{T}$ cells simply form a single homogeneous population of long lived cells ${ }^{55}$, and that because uptake of label is slow it is difficult to make any inference about the relative lifetimes of RTE and mature cells, or to estimate the efficiency with which RTE are incorporated into the mature pool. A later study by the same group ${ }^{56}$ similarly found no signal of heterogeneity in turnover within the naive T cell compartments in humans. It seems likely that only direct 
identification of RTE will allow us to quantify their dynamics in humans under replete conditions.

\section{4 |Mature naive $\mathrm{T}$ cells}

\subsection{The population dynamics of naive $\mathrm{T}$ cells in mice}

The rate at which new naive $\mathrm{T}$ cells are exported from the mouse thymus into peripheral circulation is typically assumed to be directly proportional to total thymocyte numbers. This rate of export rises from birth, peaks near 8 weeks of age and then declines exponentially, halving roughly every 150 days $6,57,58$. Once in the periphery, naive $\mathrm{T}$ cells also undergo proliferative renewal in both mice and humans. In mice it occurs with a slow kinetic that is consistent with entry into cell cycle being a Poisson process ${ }^{6}$. This mode of renewal through single divisions is also observed in memory $\mathrm{T}$ cells ${ }^{59,60}$, and contrasts with the rapid and more deterministic program of divisions that takes place during antigen-driven clonal expansion of naive $\mathrm{T}$ cells into effector and memory populations ${ }^{61-63}$.

The long-term dynamics of the naive $\mathrm{T}$ cell pools in healthy adult mice can be described remarkably well by a model pairing a declining thymic source with constant rates of division and death,

$$
\frac{\mathrm{d} N}{\mathrm{~d} t}=\theta_{0} e^{-\nu t}-\lambda N,
$$

where $\lambda$ is the net effect of of loss of naive cells through death or differentiation and cell division $^{47,64}$. Ki67 is a nuclear protein that is detectable for 3-4 days following cell division ${ }^{55,60,65,66}$, and is detectable in roughly $4 \%$ of naive CD4 and CD8 $\mathrm{T}$ cells in adult mice ${ }^{6}$. This level gives an upper bound on the rate of homeostatic division of roughly $(0.04 / 3.5) / \mathrm{d}$, or a mean interdivision time of at least 100 days. This estimate will increase if the Ki67 fraction includes any residual expression from intrathymic proliferation. The expected resi- dence times of naive CD4 and CD8 T cells (the average time taken after thymic export to leave the naive pool due to loss or differentiation) are 2 or 3 fold shorter than this ${ }^{6,47}$. Because total naive $\mathrm{T}$ cell numbers in mice fall only by a factor of two between 100 and 500 days of age ${ }^{47,64}$, this simple analysis confirms that naive cells in adult mice are sustained largely by thymic export ${ }^{47}$.

This simple model implies that naive $\mathrm{T}$ cells are ignorant of each other, but in other physiological settings there are multiple strands of evidence for competition or quorum sensing. Naive T cell numbers in thymectomised mice decline more slowly than expected from equation 2 (ref. 47). That study concluded that either cell loss rates decreased or division rates increased as numbers fell, due to an increase in the availability of homeostatic stimuli. Indeed other studies have assumed competition among naive $\mathrm{T}$ cells in mice, modelling it as a simple carrying capacity encoded as a density-dependent rate of proliferation or loss ${ }^{67,68}$.

Such models are perhaps motivated by the observation that naive $\mathrm{T}$ cells transferred to severely lymphopenic mice, or those emerging into the periphery following $\mathrm{T}$ cell depletion, proliferate much more rapidly than in replete conditions ${ }^{8,69-71}$, with a mean interdivision time of hours or days $8,72,73$, and this lymphopenia-induced proliferation (LIP) appears to slow as the naive compartment fills ${ }^{72}$. It seems likely that this slowing is due at least in part to increasing competition for resources, because the fold expansion is inversely proportional to the number of cells transferred ${ }^{73,74}$. The extent to which resourcecompetition limits homeostatic division under normal conditions, however, is unclear. In one study in mice, more than $90 \%$ of peripheral $\mathrm{T}$ cells had to be depleted before LIP was observed ${ }^{75}$ and levels of homeostatic proliferation as measured by Ki67 show very little change with mouse age as cell numbers fall due to waning thymic output (T. Hogan and B. Seddon, unpublished observations) or even following thymectomy ${ }^{43}$. 
The neonatal mouse environment might be considered lymphopenic and indeed supports the proliferation of adoptively transferred naive $T$ cells from adult mice $^{76}$, but the expansion observed in that study was accompanied by a transition to a memory-like phenotype and so cannot be the mechanism of accumulation of naive $\mathrm{T}$ cells during the first few weeks of life. Further, while naive T cell Ki67 levels are higher in neonates than in adults, SP thymocytes are also more proliferative early in life (T. Hogan and B. Seddon, unpublished observations). It is therefore unclear to what extent the rapid accumulation of naive $\mathrm{T}$ cells in very young mice is driven by a mode of lymphopenia-induced proliferation which preserves a naive phenotype, or from a highly active thymus, with associated residual expression of Ki67 deriving from the last stages of thymic development.

Understanding the nature of resource competition among naive $\mathrm{T}$ cells is complicated by their nonredundant requirements for both TCR signals ${ }^{77-80}$ and cytokines such as IL-7 ${ }^{79,81,82}$. TCR signals in CD8 and CD4 T cells derive from contact with cells presenting self-peptides in the context of Major Histocompatibility Complexes (self-pMHC-I and selfpMHC-II respectively) ${ }^{83-86}$. Determining the necessity of TCR interactions in homeostasis has historically been difficult due to the complexities of fully ablating MHC but a consensus has emerged that TCR signals are required for naive $\mathrm{T}$ cell survival under healthy conditions ${ }^{80}$. Cytokines such as IL-7 are produced by stromal cell components of primary and secondary lymphoid organs, such as follicular reticular cells ${ }^{87}$ and lymphatic endothelia ${ }^{88}$. Naive CD8 $\mathrm{T}$ cells can additionally take advantage of IL15 to support both their survival and proliferation under lymphopenic conditions ${ }^{89}$. The overall size of the $\mathrm{T}$ cell compartment appears to be influenced by the abundance of IL-7, with over-expression of IL7 leading to an increase in total peripheral numbers that is driven by changes in peripheral dynamics and not increased thymic output ${ }^{90}$. For CD4 T cells this increase is manifest in both naive and memory compartments, but the increase in CD8 T cell numbers is in memory only, perhaps in part due to conversion of naive $\mathrm{T}$ cells ${ }^{91}$.

LIP of naive CD4 and CD8 cells is driven by both TCR signaling ${ }^{92,93}$ and IL- $7^{82}$. There is also evidence that cells' interpretation of homeostatic signals is subject to dynamic tuning. Sensitivity to self-pMHC may be controlled dynamically by CD5, a negative regulator of TCR signaling ${ }^{94}$ which itself may be under feedback control from TCR signals ${ }^{79,95}$, and CD8 T cells deprived of self-pMHC class I exhibit increased sensitivity to TCR stimulation ${ }^{96}$. Similarly, IL-7 signaling may feed back to inhibit expression of the IL-7 receptor as an 'altruistic' response to homeostatic cytokine signaling ${ }^{97}$. In humans, the role of cytokines such as IL-7 and IL-15 for survival of naive cells is well established ${ }^{98}$. Whether TCR signals tune functional activity of naive $\mathrm{T}$ cells and promote their survival in a similar manner to that described in mice is not known, as we lack an appropriate experimental framework to investigate such signalling in vivo in humans.

Together these results suggest that naive $\mathrm{T}$ cell numbers are regulated through the availability of shared resources. This quorum-sensing is mediated by the interplay of at least two signals whose availabilities likely become limiting at different cell densities, and have differing impacts on survival and the propensity for proliferative renewal. It seems that competition for these signals predominantly tunes survival at or near normal cell numbers, but these stimuli drive proliferation when not limiting. We return to the issue of the 'public' or TCR-clonotype-specific nature of MHC-derived stimuli below.

\subsection{Heterogeneity in naive $\mathrm{T}$ cell population dynamics}

To add to this complexity, several experimental observations regarding naive $\mathrm{T}$ cell population dynamics cannot be explained purely with quorum-sensing models, which implicitly assume that all cells have the same rates of division and of loss at any given 
time. One is that aged naive cells in mice appear to have a survival advantage over younger naive cells in the same environment ${ }^{99}$. Another derives from an experimental system using mice in which lymphocyte precursors in the bone marrow are replaced with congenically labelled counterparts following treatment with the transplant conditioning drug busulfan, which depletes stem cells while leaving the thymus and periphery intact ${ }^{6}$. Monitoring the replacement of host cells with new donor-derived $\mathrm{T}$ cells into the peripheral $\mathrm{T}$ cell compartments allows one to follow the fates of cell populations of different ages and so to test different models of homeostatic renewal and replacement. For the case of a single, homogeneous population maintained at constant numbers, one would expect donor cells to gradually replace host cells to a stable level equal to the chimerism achieved in the upstream (progenitor) population, on a timescale determined by the rate of population turnover. However, in adult recipient mice donor-derived $\mathrm{T}$ cells populate the mature naive CD4 and CD8 T cell compartments to only $80-90 \%$ of the level expected (i.e. of the chimerism attained amongst naive precursors within the thymus $)^{6}$. Replacement is complete in other populations such as B-cells and naive $\gamma \delta \mathrm{T}$ cells (T. Hogan, M. Verheijen, B. Seddon, unpublished observations), indicating that the incomplete replacement of naive $\alpha \beta \mathrm{T}$ cells is not an artefact of the experimental system. One potential explanation of the shortfall is that the normal decline in thymic output with mouse age causes the influx of donor cells to dwindle before the chimerism in the mature naive pool can reach that in the thymus, which is established within a few weeks after bone marrow transplant. However, even for a general homogeneous birth-death models with rates of loss and division varying arbitrarily with time, thymic involution is too slow to explain the incomplete replacement ${ }^{6}$. The difference in the average behaviour of host- and donor-derived cells, together with the increased fitness of older cells ${ }^{99}$, then argues against purely homogeneous, potentially resource-limited models of turnover in which all naive cells are equally likely to divide or die within any given time interval.

Heterogeneity in homeostatic dynamics could derive from multiple sources. There may be stable phenotypic variation - that is, the naive pools comprise subpopulations with different rates of turnover that occupy distinct homeostatic niches. A putative population of host-derived 'incumbent' cells, established early in life and resistant to displacement, was invoked to explain the incomplete replacement of naive $\mathrm{T}$ cells in the busulfan chimera system ${ }^{6}$. Heterogeneity could also emerge progressively through selection or adaptation. In a pure selection scenario, natural variation in the fitness of cells exported from the thymus ${ }^{64,100,101}$ generates heterogeneity in the mature naive T cell pool which develops over an individual's lifetime through the accumulation of longer-lived or more proliferative cells. If this fitness distribution derives from cell-cell variation in the average affinity of the TCR for self peptide-MHC ${ }^{95,102}$, the naive pool may become progressively enriched for strongly self-reactive cells, potentially increasing the risk of autoimmune disease with age ${ }^{18}$. The rate at which any selection occurs will be magnified by the gradual decline in thymic output, which progressively starves the pool of new TCR specificities. In a purely adaptive scenario, naive cells are born equal and the dominant source of heterogeneity is cell age; as cells spend more time in the periphery, their fitness changes relative to younger cells in the same environment, either deterministically or stochastically through the accrual of mutations ${ }^{103}$. The distribution of fitnesses under selection or adaption might be shaped further through additional competition for resources, either globally or within TCR-specific niches.

Without tracking the fitness of individual cells with 831 age, these potential sources of heterogeneity are dif- ${ }_{832}$ ficult to distinguish experimentally. For example, ${ }_{833}$ Tsukamoto et al. ${ }^{99}$ ascribed the apparent increase in $\quad{ }^{834}$ lifespan of old cells to a process of adaptation or conditioning, and not selection. They argued that given the natural decline in thymic output and the short 
average lifespan of naive cells in young adult mice ( $\sim 4$-6 weeks for naive CD4, $\sim 8$-11 weeks for naive CD $8^{6,47,83}$ ) selection for long-lived cells should be complete in middle aged mice; yet they saw a continuous increase in fitness of cells taken from mice aged between 6 and 24 months, relative to cells in younger animals. However, with its approximately exponential decline with a half-life of roughly 6 months $^{6}$, thymic output is still appreciable in 2 year-old mice and so selection may well continue to operate into old age. This uncertainty highlights how quantitative models are potentially very useful for discriminating between candidate biological mechanisms.

One can assess the support for different models using statistical criteria, but another test of a model's strength is its ability to explain multiple independent sets of observations. Taking this approach, a recent study of ours ${ }^{64}$ compared a suite of candidate models of naive $\mathrm{T}$ cell homeostasis (Figure 2), describing constant rates of division and loss (equation 1), density-dependent rates of division or death, adaptation, selection, and population heterogeneity with incumbent cells. We confronted these models with three datasets relating to naive $\mathrm{T}$ cell homeostasis under healthy conditions or in partial lymphopenia; the kinetics of $\mathrm{T}$ cell numbers in both euthymic and thymectomised mice reported by den Braber et al. ${ }^{47}$, the kinetics of naive $\mathrm{T}$ cell replacement in busulfan chimeras of different ages, and the results of adoptive transfers of naive CD4 $\mathrm{T}$ cells from hosts of different ages, reported in Tsukamoto et al. ${ }^{99}$. Only the adaptation model was able to simultaneously explain all three datasets (Figure 2), with fitness increasing slowly on a timescale of roughly 100 days. This pace of accrual of fitness is somewhat at odds with the shorter timescales of RTE maturation, and indeed a model of a conveyor-belt mechanism of RTE dynamics, a special case of adaptation in which all cells progress to maturity (and higher fitness) after a fixed time in the periphery, explains these diverse datasets poorly ${ }^{64}$. The study also supports the conclusion of Tsukamoto et al. ${ }^{99}$ that selection alone is unable to explain the trend in naive $\mathrm{T}$ cell survival with host age.

This strong support for a dominant role for adaptation in naive $\mathrm{T}$ cell homeostasis drew on the principle of parsimony, but other homeostatic mechanisms likely operate, to different extents. In particular, as discussed above, resource competition likely regulates cell numbers as thymic output declines, although it seems this may be a relatively weak effect and only apparent under more extreme physiological perturbations. This uncertainty highlights the challenge of characterizing complexity in biological systems. Multiple mechanisms likely operate, but our ability to identify and parameterize them all simultaneously in a single unified model is limited by the number of datasets available and our ability to reliably search high-dimensional parameter spaces for the best-fitting predictions.

\subsection{Regulation of naive $\mathrm{T}$ cell numbers in humans}

There is equivocal evidence for regulation of naive $\mathrm{T}$ cell numbers through resource competition in humans. A study by Dutilh and de Boer ${ }^{104}$ used TREC measurements to infer the existence of a densitydependent homeostatic mechanism - that the net rate of loss of naive $\mathrm{T}$ cells in humans is positively correlated with cell numbers. In homogeneous models of naive $\mathrm{T}$ cell turnover the TREC frequency the average number of TRECs per T cell - is unaffected by cell death and is instead determined by the influx of TREC-rich cells from the thymus and their dilution through cell division. (Conversely, the absolute number of TRECs in an individual reflects influx and loss but not cell division, and the number of TRECs per unit volume of blood may be a useful correlate of thymic output ${ }^{105}$.) Dutilh and de Boer showed that the age-related decline in TREC frequencies in healthy humans was too rapid to be explained by thymic involution alone. They argued that the shortfall could be explained most simply by a compensatory increase in homeostatic cell division 


\section{Datasets}

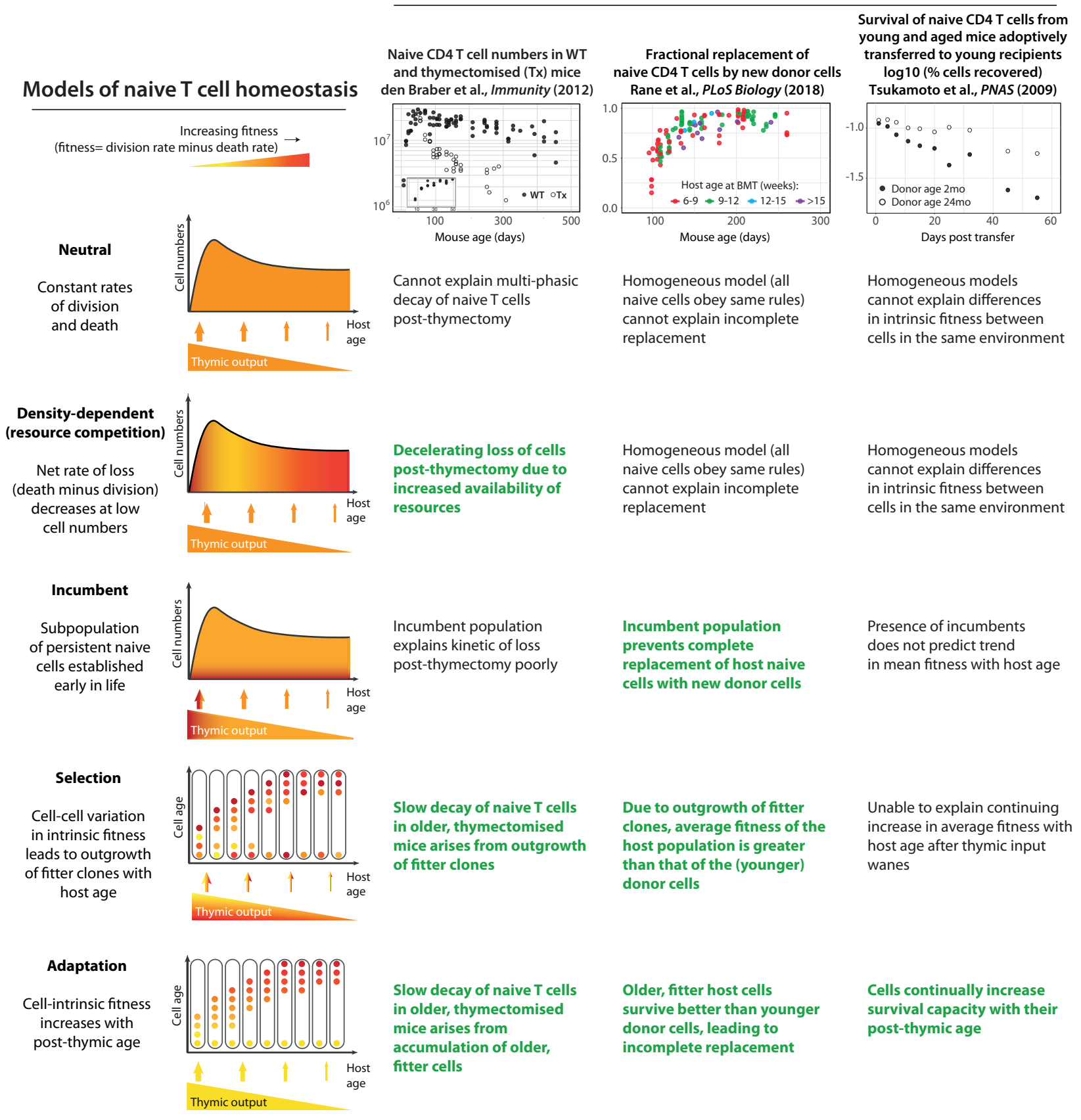

Figure 2: Comparing the ability of multiple models of naive $\mathrm{T}$ cell homeostasis to explain diverse datasets. Green, bold text indicates that the model is able to explain the corresponding dataset. Only the adaptation model is able to explain all three sets of data alone. (Figure adapted from ref. 64). 
driven by the (modest) decrease in naive cell numbers with age. Indeed one study has shown an increase in homeostatic division and decline in TRECs per PBMC after 20 years of age ${ }^{106}$. One explanation for the discrepancy is that there were differences in the ages of the individuals in each of the studies. Another explanation is the one pointed out by Dutilh and de Boer, that the TREC dynamics could also be explained by increased cell survival rather than an increase in cell division with age. In this scenario TRECs are slowly degraded within cells, and any increase in cell lifespan with host age will expose this loss and reduce TREC frequencies further. Detecting changes in cell survival would be difficult to quantify using division-labelling alone, if one relaxes the assumption that the population is in perfect equilibrium with division balancing death. Indeed any of these effects may be small, because modelling of deuterium labelling in young and old adult humans revealed surprisingly little change in the rates of division or turnover of naive CD4 and CD8 T cells with age, as their numbers fall and thymic output wanes ${ }^{107}$.

Nevertheless, Reynolds et al. ${ }^{108}$ modelled naive $\mathrm{T}$ cell homeostasis in humans assuming that quorumsensing does operate under normal conditions, mediated by competition for a finite resource of IL-7 that regulates both cell survival and homeostatic proliferation. In this model cells possess different IL-7 signalling thresholds for the two processes, which are both lognormally distributed across the population. Depending on the probability of survival $(p)$ immediately following cell division, the model predicts either a unique stable compartment size $(p>0.5)$ or if $p<0.5$ stability is followed by a bifurcation and subsequent crash in the naive $\mathrm{T}$ cell numbers in early adulthood, at an age determined by the decline in thymic output and a saturation in the rate of production of IL-7 (assumed proportional to body mass). This model predicted an upper bound on the proportion of naive cells in cycle of $0.05 \%$. Approximately $0.2-1 \%$ of naive T cells are Ki67+ in young adult humans ${ }^{43,109}$. Assuming a cell cycle duration of $12 \mathrm{~h}^{108}$ and a Ki67 lifetime of 3.5 days, these observations imply that $0.03-0.14 \%$ of naive cells are in cell cycle at any time, which is in broad agreement with the predictions of Reynolds et al..

In contrast, there is strong evidence that homeostatic proliferation contributes substantially to the reconstitution of the $\mathrm{T}$ cell compartments following therapeutic depletion ${ }^{110}$ and is manifest in the lymphopenia induced by untreated HIV infection ${ }^{111}$. Such polyclonal proliferation is commonly associated with conversion of naive cells to a memory-like phenotype with effector characteristics, which if self-reactive likely contribute to autoimmune diseases ${ }^{110}$.

\subsection{Estimating the relative contributions of thymic output and peripheral division in humans}

One of the key differences between mice and humans with regard to $\mathrm{T}$ cell homeostasis is the relative contribution of thymic output and peripheral division to the maintenance of the mature naive $\mathrm{T}$ cell pools. The thymus in a young adult mouse releases of the order $10^{6}$ cells per day ${ }^{6,15,112,113}$, which is roughly $1 \%$ of peripheral $\mathrm{T}$ cell numbers and is 2 - to 5-fold greater than the contribution of peripheral division to daily naive $\mathrm{T}$ cell production in adult mice ${ }^{6}$. Other estimates of this ratio are even higher ${ }^{47}$. In humans, however, the situation is reversed. Bains et al. ${ }^{114}$ drew on several datasets (see references therein) indicating that TREC frequencies within naive CD4 $\mathrm{T}$ cell populations show very little change up to early adulthood in humans. Pairing this observation with a general model of naive $\mathrm{T}$ cell homeostasis which assumed a homogeneous naive compartment and allowing rates of cell division and loss to vary arbitrarily with time, they showed that peripheral production exceeds that of the thymus in 1000 
young humans:

Production rate through division $=$

$$
\left(\frac{c}{\tau}-1\right) \theta(t) \simeq 2 \theta(t)
$$

where $\theta$ is the rate of export of cells from the thymus, $c \simeq 0.25$ is the average TREC content of a cell emerging from the thymus ${ }^{115}$ and $\tau \simeq 0.08$ is the estimated (and roughly constant) frequency of TRECs per naive CD4 $\mathrm{T}$ cell in the periphery up to age 20 (ref. 111). If the naive $\mathrm{T}$ cell pool is assumed to be homogeneous, the predominance of peripheral division over supplementation from the thymus is the only conclusion that can be drawn from the large difference in the average TREC content of recent thymic emigrants and mature naive cells. An analogous argument was used by den Braber et al. ${ }^{47}$, who made a very similar estimate of the TREC content of CD4+ RTE using SP thymocytes from thymectomised children, and estimated that post-thymic proliferation accounts for 5-7 times more production than thymic export in young adult humans.

Bains et al. also developed a formalism for direct estimation of thymic output using measurements of TREC frequencies and levels of Ki67 within mature naive cells ${ }^{116}$. Their formulation likely overestimates the level of thymic output roughly 7 -fold, by using an estimated Ki67 lifetime that is too low (12h). Using the developed consensus of roughly 3.5 days shifts their estimate to $\sim 70$ million cells per day in young adults, somewhat closer to the more recent estimate by den Braber et al. ${ }^{47}$ of 16 million cells per day, based on a similar principle of combining measurements of TRECs and estimates of division rates using deuterium labelling.

As in mice, it is unclear to what extents the ontogeny of the naive $\mathrm{T}$ cell pool in infant humans is driven by thymic output and peripheral expansion. Schönland et al. ${ }^{109}$ found that the frequencies of $\mathrm{Ki}^{+} 7^{+}$cells in cord blood from third-trimester neonates of 30-40 weeks gestation were initially around $10 \%$, roughly 100 fold higher than those in young adults, declining to $\sim 1 \%$ by 40 weeks gestational age. However dur- ${ }_{1039}$ ing this period they also found that TREC frequen- 1040 cies within both naive $\mathrm{CD} 4^{+}$and $\mathrm{CD} 8^{+}$cells were ${ }^{1041}$ stable, but also higher than seen in young adults. ${ }^{1042}$ The simplest interpretation of these observations is ${ }_{1043}$ that thymic output and post-thymic proliferation are ${ }_{1044}$ both greatly elevated in neonates and fall in tandem. ${ }_{1045}$ Due to the slow intracellular decay of Ki67, it is un- ${ }_{1046}$ clear whether this increased proliferation, which acts ${ }_{1047}$ to reduce TREC frequencies, occurs in the periphery ${ }_{1048}$ or late in thymic development.

\subsection{Are there TCR-specific niches in ${ }_{1050}$ the naive $\mathrm{T}$ cell pools?

While there is clear evidence that TCR interactions ${ }_{1052}$ with self-peptide-MHC (spMHC) ligands are impli- ${ }_{1053}$ cated in naive $\mathrm{T}$ cell homeostasis, the specificity of ${ }^{1054}$ these signals is unclear. If the necessary stimuli can ${ }^{1055}$ be obtained with low-affinity binding, as they ap- 1056 pear to be for positive selection in the thymus, these ${ }_{1057}$ promiscuous ligands might be considered a common ${ }_{1058}$ resource, and if access to them is limiting they medi- ${ }_{1059}$ ate quorum sensing at the level of the total compart- 1060 ment size. In contrast, any degree of specificity in 1061 TCR-mediated homeostatic stimuli opens the door ${ }_{1062}$ for a more complex picture of $\mathrm{T}$ cell homeostasis in ${ }^{1063}$ which different TCR clones compete for access to ${ }_{1064}$ diverse 'private' spMHC ligands. Due to the cross- ${ }^{1065}$ reactivity of the TCR, such niches may be overlap- 1066 ping. Any such structure may facilitate tthe main- ${ }_{1067}$ tenance of TCR repertoire diversity.

Despite the rational basis and appeal of this mecha- ${ }^{1069}$ nism, in mice there is relatively little direct experi- ${ }_{1070}$ mental evidence for the existence of specific spMHC ${ }_{1071}$ niches for $\mathrm{T}$ cell clones in the steady state, partly ${ }_{1072}$ because many studies in this area have used TCR ${ }_{1073}$ transgenic cells in unphysiologically high numbers 1074 or in lymphopenic settings. The expansions of dif- ${ }^{1075}$ ferent clonotypes are reduced when co-transferred 1076 to the same animal, suggesting a dominant role for 1077 a public resource ${ }^{73}$ and intra-clonal inhibition has ${ }_{1078}$ 
been shown not to require interactions with $\mathrm{MHC}^{117}$. However, TCR specificity can impact the ability to obtain homeostatic stimuli ${ }^{102,118}$, and TCR transgenic cells can be seen to receive weaker TCR signals in a monoclonal than in a polyclonal host mouse ${ }^{119}$, although the compounding effect of competition for IL-7 makes it hard to assess whether survival is indeed impacted by these subtle changes in the TCR signalling. Perhaps the only study to directly address the possibility of TCR-specific niches using clonal frequencies closer to physiological levels is that of Hataye et al. ${ }^{120}$, who demonstrated that the extent of proliferation of TCR transgenic T cells following transfer to normal mice was dependent on their clonal abundance.

The evidence for or against TCR-specific niches in humans is also limited, but to explore this issue Ciupe et al. ${ }^{121}$ analysed data from patients with a profound defect in thymic development whose peripheral $\mathrm{T}$ cell compartments reconstituted following thymus transplantation. Their aim was to assess the relative importance of common and TCR-specific resources in regulating the size and TCR diversity of the peripheral $\mathrm{T}$ cell pool, essentially by comparing the rates at which these quantities reach equilibrium following transplant. They concluded that the carrying capacity for a single TCR clone in isolation is approximately 1000 times the typical clone size under normal (lymphoreplete) conditions, implying that in healthy individuals, $\mathrm{T}$ cell numbers are regulated far more strongly at the population level than at the clonal level. However, their study did not distinguish naive and memory $\mathrm{T}$ cells. The latter may contain more highly expanded clones and have a strong impact on diversity estimates. It therefore is possible that the equilibration of naive $\mathrm{T}$ cell diversity occurs on a different timescale to that of the peripheral $\mathrm{T}$ cell pool as a whole.

Assuming a significant role for spMHC niche-based competition, several studies have modelled the within-host evolution of TCR clonal structure using stochastic birth-death models. Lythe et al. ${ }^{122}$ used a model of competition for a set of spMHC niches ${ }_{1121}$ and estimate naive $\mathrm{T}$ cell clone sizes in humans to ${ }_{1122}$ be of the order 10 cells, a result which is insensitive ${ }_{1123}$ to the details of niche structure and level of TCR ${ }_{1124}$ cross-reactivity by construction. This result assumes ${ }_{1125}$ a 1:25 ratio of thymic output to peripheral produc- ${ }_{1126}$ tion, which is rather low compared to experimental ${ }_{1127}$ estimates, at least in young adults (see above). The ${ }_{1128}$ estimated clone size would decrease if this ratio in- ${ }_{1129}$ creases and so their analysis could quite reasonably ${ }_{1130}$ be consistent with an average TCR clone size being ${ }^{1131}$ close to one cell. Stirk et al. ${ }^{123}$ described a model ${ }^{1132}$ in which naive $\mathrm{T}$ cells are characterised by the de- ${ }_{1133}$ gree to which their spMHC niche is shared by other ${ }_{1134}$ cells, which they refer to as the mean niche overlap ${ }_{1135}$ and might be identified with the cross-reactivity of ${ }_{1136}$ the TCR. They show that all TCR clonotypes are ${ }_{1137}$ guaranteed to go extinct within some finite time and ${ }_{1138}$ that the lower a clone's niche overlap the longer its 1139 expected residence time, due to reduced competition 1140 for resources. They argue that clones with lower ${ }_{1141}$ overlap in spMHC requirements likely have a cor- ${ }_{1142}$ respondingly low coverage of foreign peptide-MHC, ${ }_{1143}$ and so an intermediate mean niche overlap is opti- ${ }_{1144}$ mal for maintaining a diverse, long-lived repertoire ${ }_{1145}$ with effective coverage of the space of foreign epi- ${ }_{1146}$ topes. This result echoes the argument that there ${ }_{1147}$ is an optimum level of cross-reactivity of the T cell ${ }_{1148}$ receptor that results from a trade-off between the ${ }_{1149}$ high specificity needed to avoid negative selection in 1150 the thymus or the periphery, and the low specificity ${ }_{1151}$ (high cross reactivity) needed to increase the proba- ${ }_{1152}$ bility that the repertoire is able to recognise a given ${ }_{1153}$ foreign $\mathrm{pMHC}^{124}$. In a subsequent study, Stirk et ${ }_{1154}$ al. went further to derive extinction probabilities 1155 for clones as a function of their similarity in speci- ${ }_{1156}$ ficity ${ }^{125}$. 


\subsection{The onward journey - naive $\mathrm{T}$ cells constitutively generate memory cells}

Naive T cells can be recruited into effector or memory populations through cognate pMHC interactions. Memory cells divide and turn over more rapidly than naive cells in both mice and humans and so they are more amenable to analysis using DNA labelling methods. We do not review these studies here but a key observation is that memory cells, even more so than naive cells, display considerable heterogeneity in their homeostatic dynamics. Such analyses typically assume that memory populations are selfrenewing and at equilibrium, but the interpretation of label uptake kinetics, and estimates of rates of division and turnover, can be complicated or confounded if there is any influx into memory compartments. Recently it has been shown by us and others that even in the absence of overt infection, there are considerable constitutive flows from naive to memory in mice in addition to kinetic heterogeneity within both effector and central memory subsets $^{60,126}$. Gossel et al. ${ }^{60}$ studied the replacement of memory compartments following transplantation of busulfan treated adult mice with congenic bone marrow. Surprisingly, donor cells were observed to steadily infiltrate both central and effector memory compartments over the life of the hosts. In contrast to naive compartments, in which extensive replacement of host cells is observed, only around half of host memory cells are replaced by the donor influx. Nevertheless, analysing flow rates revealed the donor influx to be substantial, with $\sim 12 \%$ of $\mathrm{CM}$ and $6 \%$ of EM compartments replaced each week in young adult mice. Tonic flow into the memory pool was also reported by Kawabe et al. ${ }^{126}$, following transfer of purified naive CD4 T cells into congenic hosts. They also addressed the key issue of the identity of the antigenic drivers for this memory influx, and identifed a role for self recognition. As described above, MHC-dependent proliferation of transferred naive $\mathrm{T}$ cells from adult mice generates memory CD4 $\mathrm{T}$ cells in neonates ${ }^{76}$, and this force ${ }_{1200}$ acting on neonatal $\mathrm{T}$ cells likely contributes to the ${ }_{1201}$ early establishment of the memory pool in young 1202 mice. Significantly, Kawabe et al. showed that germ- ${ }_{1203}$ free mice possess a CD4 memory compartment of ${ }_{1204}$ comparable size to that in conventional SPF reared ${ }_{1205}$ mice, suggesting that self-driven LIP is a major con- 1206 tributor to the establishment of the memory com- ${ }_{1207}$ partment. Similarly, they showed that conversion of 1208 naive to memory in adult mice was dependent upon 1209 TCR and CD28 signalling. Treatment of mice with 1210 broad-spectrum antibiotics did not reduce the ex- 1211 tent of conversion to memory, and the authors argued $\quad 1212$ that the same self-recognition drives this flow in both ${ }_{1213}$ neonate and adult, albeit at different rates. ${ }_{1214}$

Although self recognition is one driver for establish- ${ }_{1215}$ ing and feeding the memory pool in young mice, a 1216 study of mice co-housed with pet-store mice ${ }^{127}$ re- ${ }_{1217}$ vealed enlarged memory compartments, demonstrat- 1218 ing that commensal and environmental microbes are 1219 also important drivers of the establishment, and po- ${ }_{1220}$ tentially maintenance, of the memory compartments. $\quad{ }_{1221}$ It remains to be determined whether exposure to 1222 such antigens contributes to these tonic flows into ${ }_{1223}$ memory, and what implications these flows - what- ${ }_{1224}$ ever their drivers - have for maintenance of preexist- ${ }_{1225}$ ing memory to pathogens.

\section{5 | Future directions and ${ }_{1227}$ challenges}

It is now clear that, at least in mice, the naive T cell ${ }_{1229}$ compartment is far from a simple homogeneous pool 1230 of cells awaiting activation. Instead it is a complex ${ }_{1231}$ mixture of cells at different developmental stages and ${ }_{1232}$ of diverse ages, whose population structure shifts as ${ }_{1233}$ the host ages and thymic output dwindles. It is also ${ }_{1234}$ evident that diversity in both developmental status 1235 and residence in the periphery impacts T cells' func- ${ }_{1236}$ tional and homeostatic properties. Mathematical ap- ${ }_{1237}$ proaches have played an important role in revealing 1238 
this complexity. They have also been successful in revealing the commonalities and differences in $\mathrm{T}$ cell homeostasis in experimental mouse models and humans, which would otherwise rely on distinct experimental analyses and approaches. There is also a considerable literature describing changes to the size, dynamics and TCR repertoire of naive CD4 and CD8 $\mathrm{T}$ cells that occur in old age ${ }^{128,129}$. We have not reviewed this literature but this is an area perhaps under-studied by modellers.

Precisely how heterogeneity in cellular homeostatic fitness becomes established, and its implications for the function of the $\mathrm{T}$ cell compartment as a whole remains to be fully elucidated. To what extent is diversity in fitness imposed during thymic development, and on which selection pressures act in the periphery to shape the $\mathrm{T}$ cell repertoire? Does the microenvironment play a role in tuning the behaviour of $\mathrm{T}$ cells? Or are there autonomous modifications to fitness as cells age? And what are the nature and structure of any homeostatic niches that underlie competition within and between clones for a place in the repertoire? Quantitative modelling approaches will continue to be important here, particularly as it seems likely that several such mechanisms may operate, and their combined effect may be difficult to predict intuitively.

\section{Acknowledgements}

The authors acknowledge financial support from the MRC (MR/P011225/1 to BS) and the National Institutes of Health (R01 AI093870 to AY).

\section{References}

1. Paul WE, editor (2008). Fundamental Immunology. Lippincott Williams \& Wilkins, Philadelphia, 6 edition

2. Starr TK, Jameson SC, Hogquist KA (2003).
Positive and negative selection of T cells. Annu Rev Immunol 21:139-76

3. Porritt HE, Rumfelt LL, Tabrizifard S, et al. (2004). Heterogeneity among DN1 prothymocytes reveals multiple progenitors with different capacities to generate $\mathrm{T}$ cell and non- $\mathrm{T}$ cell lineages. Immunity 20(6):735-45

4. Shen HQ, Lu M, Ikawa T, et al. (2003). T/NK bipotent progenitors in the thymus retain the potential to generate dendritic cells. J Immunol 171(7):3401-6

5. Schmitt TM, Ciofani M, Petrie HT, Zúñiga Pflücker JC (2004). Maintenance of T cell specification and differentiation requires recurrent notch receptor-ligand interactions. J Exp Med 200(4):469-79

6. Hogan T, Gossel G, Yates AJ, Seddon B (2015). Temporal fate mapping reveals age-linked heterogeneity in naive T lymphocytes in mice. Proc Natl Acad Sci U S A 112(50):E6917-26

7. Manesso E, Chickarmane V, Kueh HY, Rothenberg EV, Peterson C (2013). Computational modelling of T-cell formation kinetics: output regulated by initial proliferation-linked deferral of developmental competence. J R Soc Interface 10(78):20120774

8. Thomas-Vaslin V, Altes HK, de Boer RJ, Klatzmann D (2008). Comprehensive assessment and mathematical modeling of $\mathrm{T}$ cell population dynamics and homeostasis. J Immunol 180(4):2240-2250

9. Souza-e Silva H, Savino W, Feijóo RA, Vasconcelos ATR (2009). A cellular automatabased mathematical model for thymocyte development. PLoS One 4(12):e8233

10. Lucas B, James KD, Cosway EJ, et al. (2016). Lymphotoxin $\beta$ Receptor Controls T Cell Progenitor Entry to the Thymus. J Immunol 197(7):2665-72 
11. Donskoy E, Foss D, Goldschneider I (2003). Gated importation of prothymocytes by adult mouse thymus is coordinated with their periodic mobilization from bone marrow. $J \mathrm{Im}$ munol 171(7):3568-75

12. Peaudecerf L, Lemos S, Galgano A, et al. (2012). Thymocytes may persist and differentiate without any input from bone marrow progenitors. J Exp Med 209(8):1401-8

13. Mahtani-Patching J, Neves JF, Pang DJ, et al. (2011). PreTCR and TCR $\gamma \delta$ signal initiation in thymocyte progenitors does not require domains implicated in receptor oligomerization. Sci Signal 4(182):ra47

14. Muñoz-Ruiz M, Sumaria N, Pennington DJ, Silva-Santos B (2017). Thymic Determinants of $\gamma \delta$ T Cell Differentiation. Trends Immunol 38(5):336-344

15. Egerton M, Scollay R, Shortman K (1990). Kinetics of mature T-cell development in the thymus. Proc Natl Acad Sci U S A 87(7):2579-82

16. Sinclair C, Bains I, Yates AJ, Seddon B (2013). Asymmetric thymocyte death underlies the CD4:CD8 T-cell ratio in the adaptive immune system. Proc Natl Acad Sci US A 110(31):E2905-14

17. Pham K, Shimoni R, Charnley M, et al. (2015). Asymmetric cell division during $\mathrm{T}$ cell development controls downstream fate. J Cell Biol 210(6):933-50

18. Mandl JN, Monteiro JP, Vrisekoop N, Germain RN (2013). T cell-positive selection uses self-ligand binding strength to optimize repertoire recognition of foreign antigens. Immunity 38(2):263-74

19. Saini M, Sinclair C, Marshall D, et al. (2010). Regulation of Zap70 expression during thymocyte development enables temporal separation of CD4 and CD8 repertoire selection at different signaling thresholds. Sci Signal 3(114):ra23

20. Stritesky GL, Xing Y, Erickson JR, et al. (2013). Murine thymic selection quantified using a unique method to capture deleted T cells. Proc Natl Acad Sci U S A 110(12):4679-84

21. Sawicka M, Stritesky GL, Reynolds J, et al. (2014). From pre-DP, post-DP, SP4, and SP8 Thymocyte Cell Counts to a Dynamical Model of Cortical and Medullary Selection. Front Immunol 5:19

22. Anderson MS, Venanzi ES, Klein L, et al. (2002). Projection of an immunological self shadow within the thymus by the Aire protein. Science 298(5597):1395-401

23. Gallegos AM, Bevan MJ (2004). Central tolerance to tissue-specific antigens mediated by direct and indirect antigen presentation. $J$ Exp Med 200(8):1039-49

24. Yates AJ (2014). Theories and quantification of thymic selection. Front Immunol 5:13

25. Bosselut R (2004). CD4/CD8-lineage differentiation in the thymus: from nuclear effectors to membrane signals. Nat Rev Immunol 4(7):52940

26. Wang L, Bosselut R (2009). CD4-CD8 lineage differentiation: Thpok-ing into the nucleus. $J$ Immunol 183(5):2903-10

27. Hernández-Hoyos G, Sohn SJ, Rothenberg EV, Alberola-Ila J (2000). Lck activity controls CD4/CD8 T cell lineage commitment. Immunity 12(3):313-22

28. Legname G, Seddon B, Lovatt M, et al. (2000). Inducible expression of a p56Lck transgene reveals a central role for Lck in the differentiation of CD4 SP thymocytes. Immunity 12(5):537-46

29. Sinclair C, Seddon B (2014). Overlapping and asymmetric functions of TCR signaling during 
thymic selection of CD4 and CD8 lineages. $J$ Immunol 192(11):5151-9

30. McCaughtry TM, Wilken MS, Hogquist KA (2007). Thymic emigration revisited. J Exp Med 204(11):2513-20

31. Hare KJ, Wilkinson RW, Jenkinson EJ, Anderson G (1998). Identification of a developmentally regulated phase of postselection expansion driven by thymic epithelium. J Immunol 160(8):3666-72

32. Hogquist KA, Xing Y, Hsu FC, Shapiro VS (2015). T Cell Adolescence: Maturation Events Beyond Positive Selection. J Immunol 195(4):1351-7

33. Lio CWJ, Hsieh CS (2008). A two-step process for thymic regulatory $\mathrm{T}$ cell development. Immunity 28(1):100-11

34. Marshall D, Sinclair C, Tung S, Seddon B (2014). Differential requirement for IL-2 and IL-15 during bifurcated development of thymic regulatory T cells. J Immunol 193(11):5525-33

35. Josefowicz SZ, Lu LF, Rudensky AY (2012). Regulatory T cells: mechanisms of differentiation and function. Annu Rev Immunol 30:53164

36. van Santen HM, Benoist C, Mathis D (2004). Number of $\mathrm{T}$ reg cells that differentiate does not increase upon encounter of agonist ligand on thymic epithelial cells. $J$ Exp Med 200(10):1221-30

37. Bains I, van Santen HM, Seddon B, Yates AJ (2013). Models of self-peptide sampling by developing $\mathrm{T}$ cells identify candidate mechanisms of thymic selection. PLoS Comput Biol 9(7):e1003102

38. Picca CC, Oh S, Panarey L, et al. (2009). Thymocyte deletion can bias Treg formation toward low-abundance self-peptide. Eur J Immunol 39(12):3301-6
39. Fink PJ, Hendricks DW (2011). Post-thymic maturation: young $\mathrm{T}$ cells assert their individuality. Nat Rev Immunol 11(8):544-9

40. Boursalian TE, Golob J, Soper DM, Cooper CJ, Fink PJ (2004). Continued maturation of thymic emigrants in the periphery. Nat Immunol 5(4):418-25

41. Xing Y, Wang X, Jameson SC, Hogquist KA (2016). Late stages of $\mathrm{T}$ cell maturation in the thymus involve NF- $\kappa \mathrm{B}$ and tonic type I interferon signaling. Nat Immunol 17(5):565-73

42. Silva A, Cornish G, Ley SC, Seddon B (2014). NF- $\kappa$ B signaling mediates homeostatic maturation of new T cells. Proc Natl Acad Sci U S A 111(9):E846-55

43. Vrisekoop N, den Braber I, de Boer AB, et al. (2008). Sparse production but preferential incorporation of recently produced naive $\mathrm{T}$ cells in the human peripheral pool. Proc Natl Acad Sci U S A 105(16):6115-6120

44. Berzins SP, Boyd RL, Miller JF (1998). The role of the thymus and recent thymic migrants in the maintenance of the adult peripheral lymphocyte pool. J Exp Med 187(11):1839-48

45. Berzins SP, Godfrey DI, Miller JF, Boyd RL (1999). A central role for thymic emigrants in peripheral T cell homeostasis. Proc Natl Acad Sci U S A 96(17):9787-91

46. Parretta E, Cassese G, Santoni A, et al. (2008). Kinetics of in vivo proliferation and death of memory and naive CD8 T cells: parameter estimation based on 5-bromo-2'-deoxyuridine incorporation in spleen, lymph nodes, and bone marrow. J Immunol 180(11):7230-7239

47. den Braber I, Mugwagwa T, Vrisekoop N, et al. (2012). Maintenance of peripheral naive T cells is sustained by thymus output in mice but not humans. Immunity 36(2):288-97

48. Houston EG Jr, Higdon LE, Fink PJ (2011). 
Recent thymic emigrants are preferentially incorporated only into the depleted T-cell pool. Proc Natl Acad Sci U S A 108(13):5366-71

49. Dong J, Chen Y, Xu X, et al. (2013). Homeostatic properties and phenotypic maturation of murine CD4+ pre-thymic emigrants in the thymus. PLoS One 8(2):e56378

50. van Hoeven V, Drylewicz J, Westera L, et al. (2017). Dynamics of Recent Thymic Emigrants in Young Adult Mice. Front Immunol 8

51. Douek DC, McFarland RD, Keiser PH, et al. (1998). Changes in thymic function with age and during the treatment of HIV infection. $\mathrm{Na}$ ture 396(6712):690-5

52. Kimmig S, Przybylski GK, Schmidt CA, et al. (2002). Two subsets of naive T helper cells with distinct $\mathrm{T}$ cell receptor excision circle content in human adult peripheral blood. J Exp Med 195(6):789-94

53. Kilpatrick RD, Rickabaugh T, Hultin LE, et al. (2008). Homeostasis of the naive CD4+ $\mathrm{T}$ cell compartment during aging. $J$ Immunol 180(3):1499-1507

54. Bains I, Yates AJ, Callard RE (2013). Heterogeneity in thymic emigrants: implications for thymectomy and immunosenescence. PLoS One 8(2):e49554

55. De Boer RJ, Perelson AS (2013). Quantifying T lymphocyte turnover. J Theor Biol 327:45-87

56. Vrisekoop N, Drylewicz J, Van Gent R, et al. (2015). Quantification of naive and memory T-cell turnover during HIV-1 infection. AIDS 29(16):2071-80

57. Hsu HC, Zhang HG, Li L, et al. (2003). Age-related thymic involution in C57BL/6J $\mathrm{x} \mathrm{DBA} / 2 \mathrm{~J}$ recombinant-inbred mice maps to mouse chromosomes 9 and 10. Genes Immun $4(6): 402-10$
58. Hale JS, Boursalian TE, Turk GL, Fink PJ (2006). Thymic output in aged mice. Proc Natl Acad Sci U S A 103(22):8447-52

59. Choo DK, Murali-Krishna K, Anita R, Ahmed R (2010). Homeostatic turnover of virusspecific memory CD8 T cells occurs stochastically and is independent of CD4 T cell help. $J$ Immunol 185(6):3436-44

60. Gossel G, Hogan T, Cownden D, Seddon B, Yates AJ (2017). Memory CD4 T cell subsets are kinetically heterogeneous and replenished from naive $\mathrm{T}$ cells at high levels. eLife 6

61. Gett AV, Hodgkin PD (2000). A cellular calculus for signal integration by T cells. Nat Immunol 1(3):239-44

62. Kaech SM, Ahmed R (2001). Memory CD8+ $\mathrm{T}$ cell differentiation: initial antigen encounter triggers a developmental program in naive cells. Nat Immunol 2(5):415-22.

63. van Stipdonk MJ, Lemmens EE, Schoenberger SP (2001). Naive CTLs require a single brief period of antigenic stimulation for clonal expansion and differentiation. Nat Immunol 2(5):423-9

64. Rane S, Hogan T, Seddon B, Yates AJ (2018). Age is not just a number: Naive $\mathrm{T}$ cells increase their ability to persist in the circulation over time. PLoS Biol 16(4):e2003949

65. Pitcher CJ, Hagen SI, Walker JM, et al. (2002). Development and homeostasis of $\mathrm{T}$ cell memory in rhesus macaque. J Immunol 168(1):29-43

66. Younes SA, Punkosdy G, Caucheteux S, et al. (2011). Memory phenotype CD4 T cells undergoing rapid, nonburst-like, cytokinedriven proliferation can be distinguished from antigen-experienced memory cells. PLoS Biol 9(10):e1001171

67. Almeida ARM, Amado IF, Reynolds J, et al. (2012). Quorum-Sensing in CD4(+) T Cell 
Homeostasis: A Hypothesis and a Model. Front Immunol 3:125

68. Reynolds J, Amado IF, Freitas AA, Lythe G, Molina-París C (2014). A mathematical perspective on CD4(+) T cell quorum-sensing. $J$ Theor Biol 347:160-75

69. Miller RA, Stutman O (1984). T cell repopulation from functionally restricted splenic progenitors: 10,000-fold expansion documented by using limiting dilution analyses. $J$ Immunol 133(6):2925-32

70. Bell EB, Sparshott SM, Drayson MT, Ford WL (1987). The stable and permanent expansion of functional $\mathrm{T}$ lymphocytes in athymic nude rats after a single injection of mature T cells. $J$ Immunol 139(5):1379-84

71. Freitas AA, Rocha B (2000). Population biology of lymphocytes: the flight for survival. Annu Rev Immunol 18:83-111

72. Yates A, Saini M, Mathiot A, Seddon B (2008). Mathematical modeling reveals the biological program regulating lymphopenia-induced proliferation. J Immunol 180(3):1414-1422

73. Hogan T, Shuvaev A, Commenges D, et al. (2013). Clonally diverse $\mathrm{T}$ cell homeostasis is maintained by a common program of cell-cycle control. J Immunol 190(8):3985-93

74. Ernst B, Lee DS, Chang JM, Sprent J, Surh CD (1999). The peptide ligands mediating positive selection in the thymus control $\mathrm{T}$ cell survival and homeostatic proliferation in the periphery. Immunity 11(2):173-81

75. Bourgeois C, Stockinger B (2006). CD25+CD4+ regulatory $\mathrm{T}$ cells and memory $\mathrm{T}$ cells prevent lymphopenia-induced proliferation of naive $\mathrm{T}$ cells in transient states of lymphopenia. J Immunol 177(7):4558-66

76. Min B, McHugh R, Sempowski GD, et al.
(2003). Neonates support lymphopenia-induced proliferation. Immunity 18(1):131-40

77. Viret C, Wong FS, Janeway CA Jr (1999). Designing and maintaining the mature TCR repertoire: the continuum of selfpeptide:self-MHC complex recognition. Immunity 10(5):559-68

78. Kirberg J, Berns A, von Boehmer H (1997). Peripheral $\mathrm{T}$ cell survival requires continual ligation of the $\mathrm{T}$ cell receptor to major histocompatibility complex-encoded molecules. J Exp Med 186(8):1269-75

79. Seddon B, Zamoyska R (2002). TCR signals mediated by Src family kinases are essential for the survival of naive $\mathrm{T}$ cells. J Immunol 169(6):2997-3005

80. Martin B, Bécourt C, Bienvenu B, Lucas B (2006). Self-recognition is crucial for maintaining the peripheral CD4+ T-cell pool in a nonlymphopenic environment. Blood 108(1):270-7

81. Schluns KS, Kieper WC, Jameson SC, Lefrancois L (2000). Interleukin-7 mediates the homeostasis of naive and memory CD8 $\mathrm{T}$ cells in vivo. Nat Immunol 1(5):426-32

82. Tan JT, Dudl E, LeRoy E, et al. (2001). IL7 is critical for homeostatic proliferation and survival of naive T cells. Proc Natl Acad Sci U $S A$ 98(15):8732-7

83. Witherden D, van Oers $\mathrm{N}$, Waltzinger C, et al. (2000). Tetracycline-controllable selection of CD4(+) T cells: half-life and survival signals in the absence of major histocompatibility complex class II molecules. J Exp Med 191(2):35564

84. Polic B, Kunkel D, Scheffold A, Rajewsky K (2001). How alpha beta T cells deal with induced TCR alpha ablation. Proc Natl Acad Sci U S A 98(15):8744-8749

85. Labrecque $\mathrm{N}$, Whitfield LS, Obst R, et al. 
(2001). How much TCR does a T cell need? Immunity 15(1):71-82

86. Kieper WC, Burghardt JT, Surh CD (2004). A role for TCR affinity in regulating naive $\mathrm{T}$ cell homeostasis. J Immunol 172(1):40-4

87. Link A, Vogt TK, Favre S, et al. (2007). Fibroblastic reticular cells in lymph nodes regulate the homeostasis of naive T cells. Nat Immunol 8(11):1255-1265

88. Onder L, Narang P, Scandella E, et al. (2012). IL-7-producing stromal cells are critical for lymph node remodeling. Blood 120(24):467583

89. Saini M, Pearson C, Seddon B (2009). Regulation of $\mathrm{T}$ cell-dendritic cell interactions by IL-7 governs T-cell activation and homeostasis. Blood 113(23):5793-800

90. Mertsching E, Burdet C, Ceredig R (1995). IL7 transgenic mice: analysis of the role of IL-7 in the differentiation of thymocytes in vivo and in vitro. Int Immunol 7(3):401-14

91. Kieper WC, Tan JT, Bondi-Boyd B, et al. (2002). Overexpression of interleukin (IL)-7 leads to IL-15-independent generation of memory phenotype CD8+ T cells. J Exp Med 195(12):1533-9

92. Kieper WC, Jameson SC (1999). Homeostatic expansion and phenotypic conversion of naïve $\mathrm{T}$ cells in response to self peptide/MHC ligands. Proc Natl Acad Sci U S A 96(23):13306-11

93. Goldrath AW, Bevan MJ (1999). Low-affinity ligands for the TCR drive proliferation of mature CD8+ T cells in lymphopenic hosts. Immunity 11(2):183-90

94. Tarakhovsky A, Kanner SB, Hombach J, et al. (1995). A role for CD5 in TCR-mediated signal transduction and thymocyte selection. Science 269(5223):535-7
95. Smith K, Seddon B, Purbhoo MA, et al. (2001). Sensory adaptation in naive peripheral CD4 T cells. J Exp Med 194(9):1253-61

96. Takada K, Jameson SC (2009). Self-class I MHC molecules support survival of naive CD8 $\mathrm{T}$ cells, but depress their functional sensitivity through regulation of $\mathrm{CD} 8$ expression levels. $J$ Exp Med 206(10):2253-69

97. Park JH, Yu Q, Erman B, et al. (2004). Suppression of IL7Ralpha transcription by IL-7 and other prosurvival cytokines: a novel mechanism for maximizing IL-7-dependent $\mathrm{T}$ cell survival. Immunity 21(2):289-302

98. Lundström W, Fewkes NM, Mackall CL (2012). IL-7 in human health and disease. Semin Immunol 24(3):218-24

99. Tsukamoto H, Clise-Dwyer K, Huston GE, et al. (2009). Age-associated increase in lifespan of naive CD4 $\mathrm{T}$ cells contributes to $\mathrm{T}$ cell homeostasis but facilitates development of functional defects. Proc Natl Acad Sci U S A 106(43):18333-8

100. Dowling MR, Milutinović D, Hodgkin PD (2005). Modelling cell lifespan and proliferation: is likelihood to die or to divide independent of age? $J$ R Soc Interface 2(5):517-26

101. Dowling MR, Hodgkin PD (2009). Modelling naive T-cell homeostasis: consequences of heritable cellular lifespan during ageing. Immunol Cell Biol 87(6):445-56

102. Surh CD, Sprent J (2000). Homeostatic T cell proliferation: how far can $\mathrm{T}$ cells be activated to self-ligands? J Exp Med 192(4):F9-F14.

103. Johnson PLF, Yates AJ, Goronzy JJ, Antia R (2012). Peripheral selection rather than thymic involution explains sudden contraction in naive CD4 T-cell diversity with age. Proc Natl Acad Sci U S A 109(52):21432-7

104. Dutilh BE, de Boer RJ (2003). Decline in ex- 
cision circles requires homeostatic renewal or homeostatic death of naive $\mathrm{T}$ cells. $J$ Theor Biol 224(3):351-8

105. Ribeiro RM, Perelson AS (2007). Determining thymic output quantitatively: using models to interpret experimental T-cell receptor excision circle (TREC) data. Immunol Rev 216:21-34

106. Murray JM, Kaufmann GR, Hodgkin PD, et al. (2003). Naive T cells are maintained by thymic output in early ages but by proliferation without phenotypic change after age twenty. Immunol Cell Biol 81(6):487-95

107. Westera L, van Hoeven V, Drylewicz J, et al. (2015). Lymphocyte maintenance during healthy aging requires no substantial alterations in cellular turnover. Aging Cell 14(2):219-27

108. Reynolds J, Coles M, Lythe G, Molina-París C (2013). Mathematical Model of Naive T Cell Division and Survival IL-7 Thresholds. Front Immunol 4:434

109. Schönland SO, Zimmer JK, Lopez-Benitez CM, et al. (2003). Homeostatic control of T-cell generation in neonates. Blood 102(4):1428-34

110. Jones JL, Thompson SAJ, Loh P, et al. (2013). Human autoimmunity after lymphocyte depletion is caused by homeostatic T-cell proliferation. Proc Natl Acad Sci U S A 110(50):20200-5

111. Douek DC, Betts MR, Hill BJ, et al. (2001). Evidence for increased $\mathrm{T}$ cell turnover and decreased thymic output in HIV infection. $J$ Immunol 167(11):6663-8

112. Scollay RG, Butcher EC, Weissman IL (1980). Thymus cell migration. Quantitative aspects of cellular traffic from the thymus to the periphery in mice. Eur J Immunol 10(3):210-8

113. Graziano M, St-Pierre Y, Beauchemin C, Desrosiers M, Potworowski EF (1998). The fate of thymocytes labeled in vivo with CFSE. Exp Cell Res 240(1):75-85

114. Bains I, Antia R, Callard R, Yates AJ (2009). Quantifying the development of the peripheral naive CD4+ T-cell pool in humans. Blood $113(22): 5480-5487$

115. Junge S, Kloeckener-Gruissem B, Zufferey R, et al. (2007). Correlation between recent thymic emigrants and CD31+ (PECAM-1) CD4+ T cells in normal individuals during aging and in lymphopenic children. Eur $J$ Immunol 37(11):3270-3280

116. Bains I, Thiébaut R, Yates AJ, Callard R (2009). Quantifying thymic export: combining models of naive $\mathrm{T}$ cell proliferation and TCR excision circle dynamics gives an explicit measure of thymic output. J Immunol 183(7):432936

117. Dummer W, Ernst B, LeRoy E, Lee D, Surh C (2001). Autologous regulation of naive T cell homeostasis within the $\mathrm{T}$ cell compartment. $J$ Immunol 166(4):2460-8

118. Troy AE, Shen H (2003). Cutting edge: homeostatic proliferation of peripheral T lymphocytes is regulated by clonal competition. J Immunol $170(2): 672-6$

119. Sinclair C, Saini M, Schim van der Loeff I, Sakaguchi S, Seddon B (2011). The long-term survival potential of mature $\mathrm{T}$ lymphocytes is programmed during development in the thymus. Sci Signal 4(199):ra77

120. Hataye J, Moon JJ, Khoruts A, Reilly C, Jenkins MK (2006). Naive and memory CD4+ T cell survival controlled by clonal abundance. Science $312(5770): 114-6$

121. Ciupe SM, Devlin BH, Markert ML, Kepler TB (2009). The dynamics of T-cell receptor repertoire diversity following thymus transplan- 
tation for DiGeorge anomaly. PLoS Comput Biol 5(6):e1000396

122. Lythe G, Callard RE, Hoare RL, Molina-París C (2016). How many TCR clonotypes does a body maintain? J Theor Biol 389:214-24

123. Stirk ER, Molina-París C, van den Berg HA (2008). Stochastic niche structure and diversity maintenance in the $\mathrm{T}$ cell repertoire. $J$ Theor Biol 255(2):237-49

124. De Boer RJ, Perelson AS (1993). How diverse should the immune system be? Proc Biol Sci 252(1335):171-175

125. Stirk ER, Lythe G, van den Berg HA, MolinaParís C (2010). Stochastic competitive exclusion in the maintenance of the naïve $\mathrm{T}$ cell repertoire. J Theor Biol 265(3):396-410

126. Kawabe T, Jankovic D, Kawabe S, et al. (2017). Memory-phenotype CD4+ T cells spontaneously generated under steady-state conditions exert innate TH1-like effector function. Sci Immunol 2(12)

127. Beura LK, Hamilton SE, Bi K, et al. (2016). Normalizing the environment recapitulates adult human immune traits in laboratory mice. Nature 532(7600):512-6

128. Goronzy JJ, Fang F, Cavanagh MM, Qi Q, Weyand CM (2015). Naive T cell maintenance and function in human aging. J Immunol 194(9):4073-80

129. Goronzy JJ, Weyand CM (2017). Successful and Maladaptive T Cell Aging. Immunity 46(3):364-378 